\title{
Solvatochromic Parameters of the Binary Mixtures of Imidazolium Chloride Ionic Liquid Plus Molecular Solvent
}

\author{
Jingyi Hu, Wei Zhu, Qiwei Yang*, Guoping Qian and Huabin Xing
}

\begin{abstract}
Key Laboratory of Biomass Chemical Engineering of Ministry of Education, Department of Chemical and Biological Engineering, Zhejiang University, Hangzhou 310027, China
\end{abstract}

\begin{abstract}
Imidazolium-based chloride ionic liquids (ILs) have exhibited remarkable performance in several important applications such as biomass dissolution and extraction, but their large viscosity is a non-negligible problem. Adding molecular co-solvents into chloride ILs is effective in reducing viscosity; nevertheless, understanding of the accompanied change of thermodynamic polarity is quite few. Therefore, in this work we reported three Kamlet-Taft solvatochromic parameters, including dipolarity/polarizability $\left(\pi^{*}\right)$, hydrogen-bond acidity $(\alpha)$ and hydrogen-bond basicity $(\beta)$, for the binary mixtures of several imidazolium-based chloride ILs plus either dipolar protic solvents (water and methanol) or dipolar aprotic solvents (dimethyl sulfoxide, $\mathrm{N}, \mathrm{N}$-dimethylformamide and acetonitrile). The results demonstrated that those parameters could be altered by the structure of IL and type of co-solvent owing to the solute-solvent and solventsolvent interactions. The structure of alkyl chain of cation had considerable impact on the $\pi^{*}$ variation of IL aqueous solution against IL concentration but hardly affected other mixtures. Moreover, remarkable preferential solvation of probes was observed for $\beta$ and $\alpha$ in the mixtures of $\mathrm{IL}$ and dipolar aprotic co-solvents, whereas the hydrogen-bond interactions between IL and dipolar protic co-solvent enabled the preferential solvation to be alleviated and resulted in more linear variation of $\beta$ and $\alpha$ against the molar fraction of IL. The results not only contribute to a better understanding of the effect of co-solvent on imidazolium-based chloride ILs, but also are instructive for improving the thermodynamic performance of IL-based applications via providing IL+co-solvent mixtures with desirable physicochemical properties.
\end{abstract}

Keywords: Polarity, hydrogen bond, basicity, acidity, preferential salvation.

\section{INTRODUCTION}

Nowadays, ionic liquids (ILs) have drawn a great deal of prevalence in various chemical processes because of their unique properties such as insignificant vapor pressure, wide liquid range, good thermal stability and so on [1-4]. In particular, among all investigated ILs, substantial attention has been attached to imidazolium-based chloride ILs. Through a one-step reaction, this kind of ILs can be easily synthesized with economic feasibility. More importantly, compared with other ILs, they have significant advantage of stronger hydrogen-bond basicity so as to outperform others in many important applications. Imidazolium-based chlorides have better dissolving capacity towards cellulose and lignin than most of other ILs, which facilitates the processing and transformation of biomass in high efficiency [5, 6]. Their high affinity for alcohols and phenolics provides opportunities for azeotrope separations and purification of bioactive substances [7, 8]. Moreover, good solubility of metal compounds in ILs enables enhanced catalytic reaction performance to be achieved $[9,10]$.

However, the fact that the viscosity of imidazoliumbased chloride ILs is very high imposes restriction on dissolving and mass-transfer processes. Blending neat

*Address correspondence to this author at the Key Laboratory of Biomass Chemical Engineering of Ministry of Education, Department of Chemical and Biological Engineering, Zhejiang University, Hangzhou 310027, China; Tel: 86571-8795-1225; Fax: 86-571-8795-2375; E-mail: yangqw@zju.edu.cn
ILs with molecular solvents to form IL+cosolvent mixtures is supposed to be a good strategy to boost extensive applications in terms of kinetics owing to the remarkably reduced viscosity [11-13]. Nevertheless, an important issue, how the polarity of mixtures differs with the pure imidazolium-based chloride ILs has not been well elucidated, which limits the understanding of these mixtures and their applications in terms of thermodynamics.

Till now, the most widely used method to study the polarity of solvents is solvatochromism method based on the variation of ultraviolet absorption of probe molecules aroused by interactions of probe solute molecules with solvent molecules. As a general description to embody overall strength of solute-solvent interactions, polarity can hardly be described by a single parameter [14]. To figure out this problem, Kamlet and Taft decomposed polarity into three parameters [15-17], namely dipolarity/polarizability $\left(\pi^{\star}\right)$, hydrogen-bond acidity $(\alpha)$, and hydrogen-bond basicity $(\beta)$, with the use of three different solvatochromic probes. These parameters have been determined for many pure imidazolium-based or pyridinium-based ILs as well as their mixtures with cosolvents [18-29], and have been successfully engaged in correlation of various chemical phenomena like extraction equilibrium, chemical reaction rate, and solubility [22, $30,31]$. However, these researches mainly focused on anions like tetrafluoroborate $\left(\mathrm{BF}_{4}^{-}\right)$, hexafluorophosphate $\left(\mathrm{PF}_{6}^{-}\right)$, trifluoromethanesulfonate $\left(\mathrm{TfO}^{-}\right)$, 
bis(trifluoromethylsulfonyl) amide $\left(\mathrm{NTf}_{2}{ }^{-}\right)$and carboxylate (RCOO') whereas ILs comprising chloride anion $\left(\mathrm{Cl}^{-}\right)$were rarely involved [32].

In this study, a systematic exploration on the Kamlet-Taft solvatochromic parameters of imidazoliumbased chloride $\mathrm{IL}+$ cosolvent mixtures was carried out with the use of three kinds of probes (Figure 1). We investigated three types of imidazolium-based chloride ILs, 1-butyl-3-methylimidazolium chloride ([Bmim]Cl), 1hexyl-3-methylimidazolium chloride $([\mathrm{Hmim}] \mathrm{Cl})$ and 1 allyl-3-methylimidazolium chloride ([Amim]Cl) mixed with dipolar protic solvents (water and methanol) or dipolar aprotic solvents (dimethyl sulfoxide, $N, N$ dimethylformamide and acetonitrile). The structures of ILs are shown in Figure 2. The effects of IL structures and cosolvent types in binary mixtures on the variation of solvatochromic parameters though solute-solvent and solvent-solvent mechanisms were discussed.

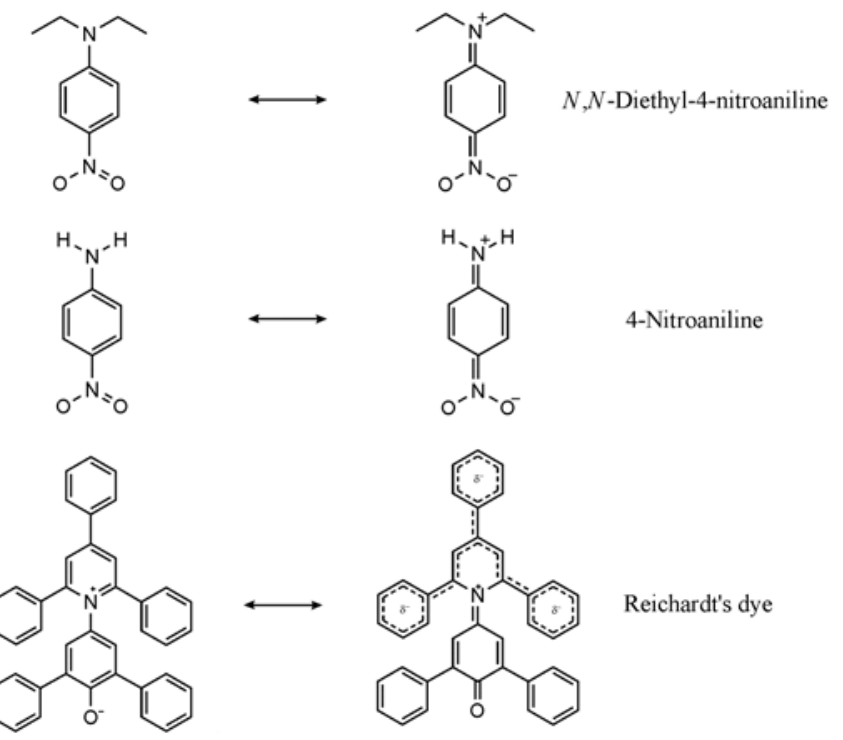

Figure 1: Structures of solvatochromic probes.

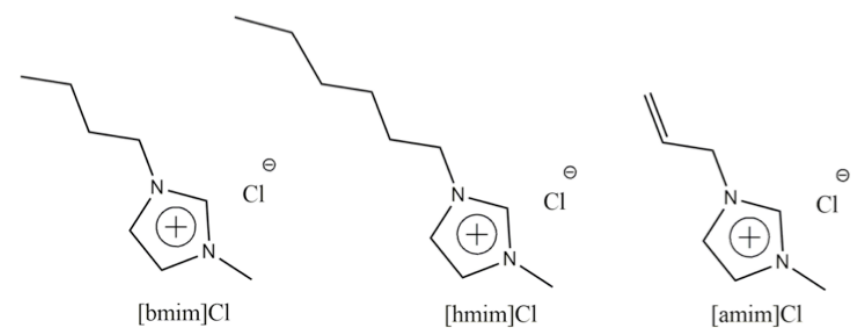

Figure 2: Structures of imidazolium-based chloride ILs.

\section{EXPERIMENTAL METHODS}

\subsection{Materials}

1-butyl-3-methylimidazolium chloride >99\%), 1-hexyl-3-methylimidazolium

([Bmim]Cl, chloride
$([\mathrm{Hmim}] \mathrm{Cl},>99 \%)$ and 1-allyl-3-methylimidazolium chloride $([\mathrm{Amim}] \mathrm{Cl},>99 \%)$ were purchased from Green Chemistry and Catalysis, LICP, CAS. Dichloromethane was obtained from Sinopharm Chemical Reagent Co., Ltd. The indicator probes for the Kamlet-Taft solvatochromic experiments were 4-nitroaniline (99\%, Aldrich), N,N-diethyl-4-nitroaniline (99\%, Oakwood Products, Inc.) and 2,6-diphenyl-4-(2,4,6-triphenyl-Npyridino) phenolate (Reichardt's dye) (99\%, Chemika). Purified water was obtained from Wahaha Group Co., Ltd. (Hangzhou, China). Methanol $(\mathrm{MeOH}, 99.5 \%)$ and $\mathrm{N}, \mathrm{N}$-dimethylformamide (DMF, $99.5 \%$ ) were purchased from Sinopharm Chemical Reagent Co., Ltd. (Shanghai, China). Acetonitrile (ACN, 99.5\%) was purchased from Lingfeng Co., Ltd. (Shanghai, China) and dimethylsulfoxide (DMSO, 99.5\%) was purchased from Haishuo Co., Ltd. (Wuxi, China).

\subsection{Method}

A certain amount of probe-dichloromethane solution, formulated by dissolving solvatochromic probes into dichloromethane solvent, was added to a small vessel followed by an entire evaporation of dichloromethane. Samples with moderate concentration could be achieved when adding neat ILs or $\mathrm{IL+cosolvent} \mathrm{mixtures} \mathrm{into} \mathrm{the} \mathrm{vessel,} \mathrm{which} \mathrm{was}$ ready to be shifted to a quartz cuvette for UV analysis. An external super circular water-bath was used to maintain temperature at $308.15 \pm 0.1 \mathrm{~K}$. Then the maximum absorption wavelength of each sample was recorded by ultraviolet-visible spectrum scanning. Scanning should be repeated for seven times to eliminate measurement deviation. All the ILs should be dried under high vacuum for $24 \mathrm{~h}$ at $435.15 \mathrm{~K}$ prior to solvatochromic experiments.

\section{RESULTS AND DISCUSSION}

\subsection{Dipolarity/Polarizability $\left(\pi^{\star}\right)$}

The usage of dipolarity/polarizability $\left(\pi^{*}\right)$ was to describe the non-specific parts of van der Waals interaction, such as dispersion, induction and electrostatic interaction [17]. $\pi^{\star}$ value could be obtained from the spectroscopic shift of $\mathrm{N}, \mathrm{N}$-diethyl-4-nitroaniline (DENA) by Eq. (1):

$$
\pi^{*}=8.649-0.31 v_{\text {DENA }}
$$

Where, $v_{\text {DENA }}$ was the maximum absorption wave number of DENA in solvent. The $\pi^{\star}$ values of neat imidazolium-based chloride ILs and cosolvents were 
Table 1: Solvatochromic Parameters for Pure ILs and Cosolvents

\begin{tabular}{|c|c|c|c|}
\hline Solvents & Dipolarity/Polarizability $\left(\pi^{\star}\right)$ & Hydrogen-Bond Basicity $(\boldsymbol{\beta})$ & Hydrogen-Bond Acidity $(\boldsymbol{\alpha})$ \\
\hline \hline$[\mathrm{Bmim}] \mathrm{Cl}[22]$ & 1.10 & 0.87 & 0.47 \\
\hline$[\mathrm{Hmim}] \mathrm{Cl}[20]$ & 1.02 & 0.94 & 0.48 \\
\hline$[\mathrm{Amim}] \mathrm{Cl}[33]$ & 1.17 & 0.83 & 0.46 \\
\hline $\mathrm{H}_{2} \mathrm{O}$ & 1.36 & 0.14 & 1.00 \\
\hline $\mathrm{MeOH}$ & 0.72 & 0.60 & 0.38 \\
\hline $\mathrm{ACN}$ & 0.78 & 0.39 & 0.15 \\
\hline $\mathrm{DMSO}$ & 1.01 & 0.72 & 0.13 \\
\hline $\mathrm{DMF}$ & 0.89 & 0.71 & \\
\hline
\end{tabular}

listed in Table 1. Seen from the table, except for $\mathrm{H}_{2} \mathrm{O}$, $\pi^{\star}$ values of pure ILs were normally higher than those of pure cosolvents.

In general, there would be a specific solvation microsphere around spectroscopic probe due to the solute-solvent interactions. The solvatochromic parameters from the response of probe molecules were determined by the solvent composition of solvation microsphere by Eq. (2) [27]:

$$
R=X_{1} R_{1}+X_{2} R_{2}
$$

Where, $R$ was the integrated response in binary mixture. $R_{1}$ and $R_{2}$ were responses of probes in two pure solvent components while $X_{1}$ and $X_{2}$ referred to the molar fractions of two solvents in solvation shell, respectively. Therefore, if $\pi^{\star}$ value in a binary mixture was linearly related to the molar fraction of solvent, it

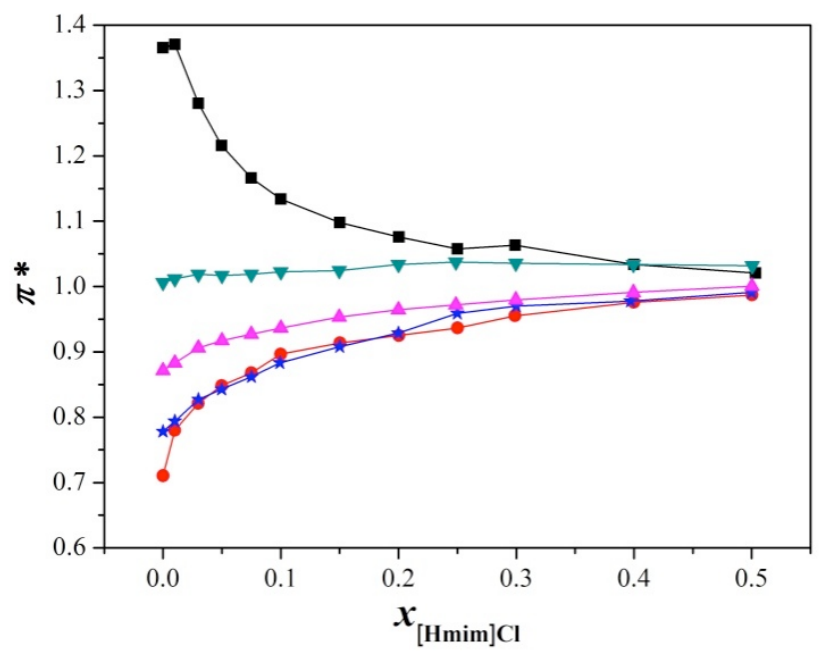

Figure 3: The performance of dipolarity/polarizability $\left(\pi^{\star}\right)$ of $[\mathrm{Hmim}] \mathrm{Cl}+$ cosolvent mixtures over the molar fraction of $[\mathrm{Hmim}] \mathrm{Cl}\left(x_{[\mathrm{Hmim}] \mathrm{Cl}}\right)$ at $308 \mathrm{~K}$ : black line $\left(\mathrm{H}_{2} \mathrm{O}\right)$, red line $(\mathrm{MeOH})$, blue line $(\mathrm{ACN})$, green line (DMSO) and rose line (DMF). illustrated a good consensus between the solvent composition of solvation microsphere around probe molecule and that of the mixture bulk, that was to be conceived as "ideal condition". Otherwise, in the occasion that local concentration of solvation microenvironment underwent a deviation from bulk concentration, preferential solvation arose.

Figures 3 and 4 described the $\pi^{*}$ values of two types of imidazolium-base chlorides ILs, [Hmim] Cl and [Amim] $\mathrm{Cl}$, plus different cosolvents. [Hmim]Cl was picked as a representative for in-depth analysis. It was noteworthy that since $[\mathrm{Hmim}] \mathrm{Cl}$ was too viscous to be hardly flowable at experiment temperature of $308 \mathrm{~K}$, we aimed at molar fraction of ILs up to 0.5. Seen from Figure 3, each $[\mathrm{Hmim}] \mathrm{Cl}+$ cosolvent mixture experienced its own characteristic. A linear relationship was found between the $\pi^{\star}$ of $[\mathrm{Hmim}] \mathrm{Cl}+\mathrm{DMSO}$ mixture

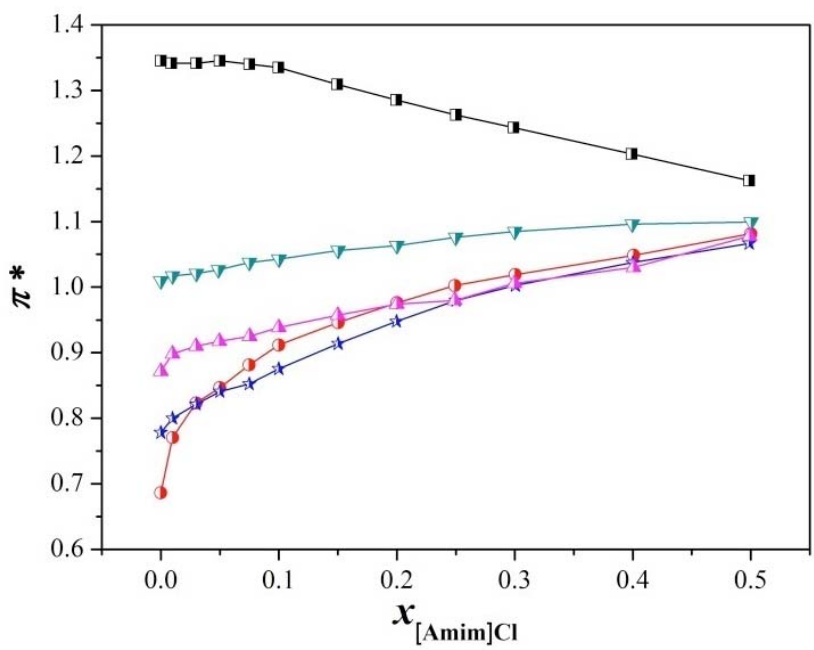

Figure 4: The performance of dipolarity/polarizability $\left(\pi^{\star}\right)$ of [Amim] $\mathrm{Cl}+$ cosolvent mixtures over the molar fraction of [Amim] $\mathrm{Cl}\left(x_{[\text {Amim]CI }}\right)$ at 308K: black line $\left(\mathrm{H}_{2} \mathrm{O}\right)$, red line $(\mathrm{MeOH})$, blue line $(\mathrm{ACN})$, green line (DMSO) and rose line (DMF). 
and the molar fraction of $[\mathrm{Hmim}] \mathrm{Cl}\left(x_{[\mathrm{Hmim}] \mathrm{Cl}}\right)$, indicating that the solvent composition of solvation microsphere around DENA was almost the same as bulk solvent composition. In fact, for these five cosolvents, $\pi^{\star}$ value for DMSO was closest to that for $[\mathrm{Hmim}] \mathrm{Cl}$. When dissolving DENA into [Hmim]Cl+DMSO mixture, by reason that DENA could form almost the same interactions with $[\mathrm{Hmim}] \mathrm{Cl}$ and $\mathrm{DMSO}$, the proportion of $[\mathrm{Hmim}] \mathrm{Cl}$ to DMSO in solvation shell around probe molecule reached a consistency with the bulk of mixture, which well accounted for the "ideal condition".

For the other mixture systems, the performances turned out to be nonlinear. With the fact that $\pi^{\star}$ of $[\mathrm{Hmim}] \mathrm{Cl}$ surpassed that of $\mathrm{MeOH}, \mathrm{ACN}$ or DMF, the addition of $[\mathrm{Hmim}] \mathrm{Cl}$ in cosolvents could incur an increase of $\pi^{*}$. Preferential salvation was regarded to take place since $\pi^{\star}$ were found to be higher than ideal behaviors, which could be ascribed to a more favorable interaction between DENA and $\mathrm{IL}$ than interactions between DENA and cosolvents. $[\mathrm{Hmim}] \mathrm{Cl}+\mathrm{H}_{2} \mathrm{O}$ mixture demonstrated that DENA was predominated by interaction with IL as well. $\pi^{*}$ in $[\mathrm{Hmim}] \mathrm{Cl}+\mathrm{H}_{2} \mathrm{O}$ expressed a gradual decline with the addition of [Hmim] $\mathrm{Cl}$ and was always below the ideal $\pi^{\star}$, which signified $x_{[\mathrm{Hmim}] \mathrm{Cl}}$ in solvation microenvironment was higher than that in the bulk of mixture.

Compared with Figures 3 and $\mathbf{4}$, among different $\mathrm{IL}+$ cosolvent mixtures, the $\pi^{\star}$ values of $\mathrm{IL}+\mathrm{H}_{2} \mathrm{O}$ mixtures distinguished from each other most obviously over IL concentration, so we targeted $\mathrm{H}_{2} \mathrm{O}$ to discuss the effect of IL structures on dipolarity/polarizability. Additional data of $[\mathrm{Bmim}] \mathrm{Cl}$ for comparison came from literature [32]. In general, $\pi^{\star}$ values of mixtures accorded with those of neat ILs, for example, [Hmim]Cl had the smallest $\pi^{\star}$, resulting in $\pi^{\star}$ value of $[\mathrm{Hmim}] \mathrm{Cl}+\mathrm{H}_{2} \mathrm{O}$ mixture ranking the smallest among the three ones. Observed from Figure 5, despite the same downturn of $\pi^{\star}$ with the adding of ILs in all three $\mathrm{IL}+\mathrm{H}_{2} \mathrm{O}$ mixtures, the tendencies showed some differences. In system of [Amim] Cl plus $\mathrm{H}_{2} \mathrm{O}$, a linear decrease of $\pi^{\star}$ over the addition of $[\mathrm{Amim}] \mathrm{Cl}$ concentration was emerged, while for $[\mathrm{Bmim}] \mathrm{Cl}+\mathrm{H}_{2} \mathrm{O}$ or $[\mathrm{Hmim}] \mathrm{Cl}+\mathrm{H}_{2} \mathrm{O}$ system the downtrend was characterized by a gradually declining slope. Particularly in $[\mathrm{Hmim}] \mathrm{Cl}+\mathrm{H}_{2} \mathrm{O}$ mixture, $\pi^{*}$ set out to drop rapidly when the molar fraction of $[\mathrm{Hmim}] \mathrm{Cl}$ was quite low, thereby leading $\pi^{\star}$ to a highly nonlinear shift. These results revealed that the small variation of cationic chain of ILs with the same chloride anion was able to induce an obvious change in dipolarity/polarizability.

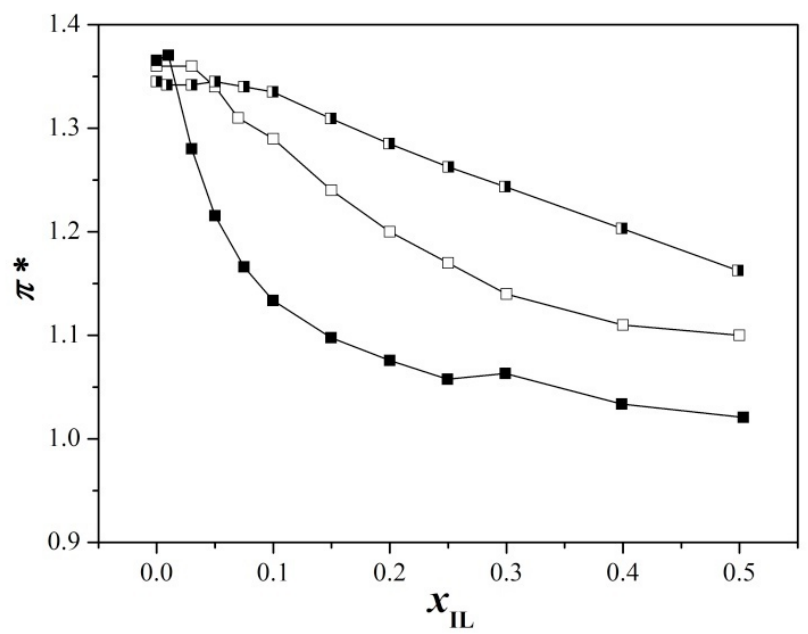

Figure 5: The effect of ILs on the performance of dipolarity/polarizability $\left(\pi^{\star}\right)$ of $\mathrm{IL}+\mathrm{H}_{2} \mathrm{O}$ mixtures over the molar fraction of $\mathrm{IL}\left(x_{\mathrm{IL}}\right)$ at $308 \mathrm{~K}$ : open $([\mathrm{Bmim}] \mathrm{Cl})$, solid $([\mathrm{Hmim}] \mathrm{Cl})$ and semi-solid ([Amim]Cl).

Among the above mentioned ILs, $[\mathrm{Hmim}] \mathrm{Cl}$ had the strongest hydrophobicity owing to the longest saturated alkyl in cationic chain. The hydrophobic property not only incurred easy aggregation of $[\mathrm{Hmim}] \mathrm{Cl}$ due to confined dissociation of $[\mathrm{Hmim}] \mathrm{Cl}$ in $\mathrm{H}_{2} \mathrm{O}$ but also rendered DENA, a relatively hydrophobic probe molecule, more prone to react with $[\mathrm{Hmim}] \mathrm{Cl}$ rather than $\mathrm{H}_{2} \mathrm{O}$. The combined effect generated the fact that $[\mathrm{Hmim}] \mathrm{Cl}$ concentration in solvation microsphere around probe molecule was significantly greater than that in the bulk of mixture, indicating that probe molecule DENA was preferentially solvated by $[\mathrm{Hmim}] \mathrm{Cl}$ in $[\mathrm{Hmim}] \mathrm{Cl}_{+} \mathrm{H}_{2} \mathrm{O}$ mixture. Because $\pi^{\star}$ value of $[\mathrm{Hmim}] \mathrm{Cl}$ was smaller than $\mathrm{H}_{2} \mathrm{O}$, preferential solvation provided illustration to the negative deviation of $\pi^{*}$ in $[\mathrm{Hmim}] \mathrm{Cl}+\mathrm{H}_{2} \mathrm{O}$ mixture from the ideal performance. Compared to $[\mathrm{Hmim}] \mathrm{Cl}$, the shorter cationic alkyl chain of $[\mathrm{Bmim}] \mathrm{Cl}$ made it more hydrophilic. Hence, DENA was less dominated by interaction with $[\mathrm{Bmim}] \mathrm{Cl}$, and the degree of nonlinearity of $\pi^{*}$ over the IL concentration was apparently relieved in $[\mathrm{Bmim}] \mathrm{Cl}+\mathrm{H}_{2} \mathrm{O}$ mixture. As the carbon chain length of $[\mathrm{Amim}] \mathrm{Cl}$ went down to three, the further enhanced hydrophilicity was supposed to largely improve dissociation of $[\mathrm{Amim}] \mathrm{Cl}$ in $\mathrm{H}_{2} \mathrm{O}$. Moreover, $[\mathrm{Amim}] \mathrm{Cl}$ possessed an unsaturated double bond, the polarizability of which was stronger than single bond. In consequence, it was not very much likely to furnish $[\mathrm{Amim}] \mathrm{Cl}$ with possible preference toward solvation of probe molecule. The local concentration of $[\mathrm{Amim}] \mathrm{Cl}$ in solvent micro-shell was 
approaching that in the mixture bulk, bringing about a linearly reduction of $\pi^{*}$ along with the rising of IL concentration.

\subsection{Hydrogen-Bond Basicity $(\beta)$}

Hydrogen-bond basicity could be defined as the ability of hydrogen-bond acceptor to donate electron pairs. In Kamlet-Taft theory, gauging both spectroscopic shifts of 4-nitroaniline (NA) and DENA could acquire hydrogen-bond basicity $(\beta)$ by Eq. (3):

$\beta=-0.357 v_{N A}-1.176 \pi^{*}+11.12$

Where $v_{\text {NA }}$ was the maximum absorption wave number of NA in solvent and $\pi^{*}$ was the obtained dipolarity/polarizability by DENA. Also displayed were $\beta$ values of pure imidazolium-based chloride ILs and cosolvents in Table $\mathbf{1}$ that told the all cosolvents selected had smaller values of $\beta$ than ILs.

To the best of knowledge, $\beta$ was primarily susceptible to the choice of anions of ILs [18]. Therefore, $[\mathrm{Hmim}] \mathrm{Cl}$ and $[\mathrm{Amim}] \mathrm{Cl}$ who just varied in the cationic chain length with chloride anion exerted insignificant influence on $\beta$ of mixtures in the same cosolvent as exhibited in Figures $\mathbf{6}$ and 7. Identical to dipolarity/polarizability, we used $[\mathrm{Hmim}] \mathrm{Cl}+$ cosolvent systems to discuss the effect of cosolvents on the variation and mechanism of hydrogen-bond basicity. Figure 6 revealed that through all $[\mathrm{Hmim}] \mathrm{Cl}+$ cosolvent systems, $\beta$ ascended with the enrollment of $[\mathrm{Hmim}] \mathrm{Cl}$ thanks to the fact that $\beta$ of $[\mathrm{Hmim}] \mathrm{Cl}$ was stronger than any of these cosolvents. In $[\mathrm{Hmim}] \mathrm{Cl}_{+} \mathrm{H}_{2} \mathrm{O}$ and

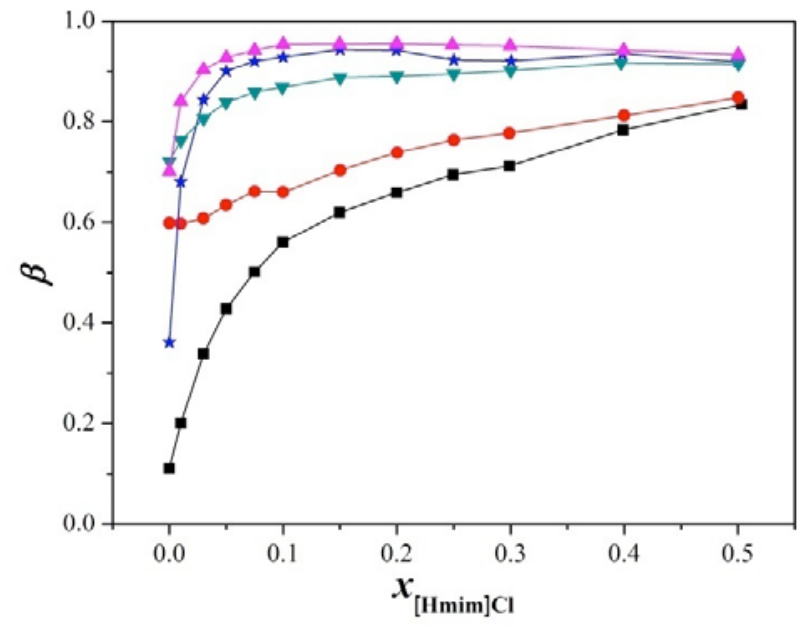

Figure 6: The performance of hydrogen-bond basicity $(\beta)$ of [Hmim] $\mathrm{Cl}+$ cosolvent mixtures over the molar fraction of $[\mathrm{Hmim}] \mathrm{Cl}\left(x_{[\mathrm{Hmim}] \mathrm{Cl}}\right)$ at $308 \mathrm{~K}$ : black line $\left(\mathrm{H}_{2} \mathrm{O}\right)$, red line $(\mathrm{MeOH})$, blue line $(\mathrm{ACN})$, green line (DMSO) and rose line (DMF).
$[\mathrm{Hmim}] \mathrm{Cl}+\mathrm{MeOH}$ mixtures, the upward trend of $\beta$ was relatively gentle, while in the other mixtures, $\beta$ increased rapidly with adding small amount of $[\mathrm{Hmim}] \mathrm{Cl}$ and then rose slowly or remained unchanged afterwards.

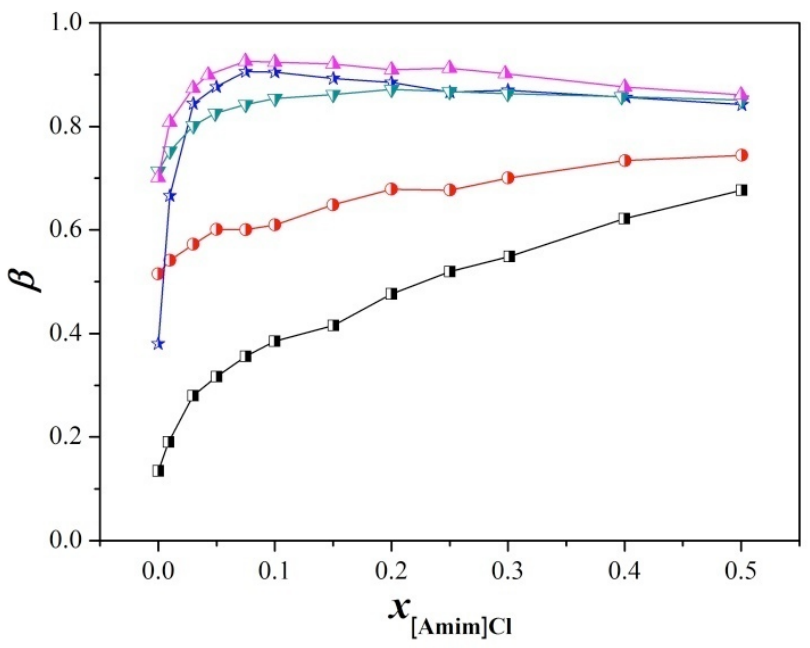

Figure 7: The performance of hydrogen-bond basicity $(\beta)$ of $[$ Amim $] \mathrm{Cl}+$ cosolvent mixtures over the molar fraction of [Amim]Cl $\left(x_{[\mathrm{Amim}] \mathrm{Cl}}\right)$ at $308 \mathrm{~K}$ : black line $\left(\mathrm{H}_{2} \mathrm{O}\right)$, red line $(\mathrm{MeOH})$, blue line $(\mathrm{ACN})$, green line (DMSO) and rose line (DMF).

Further analysis helped us to give insight into these phenomena. We knew that the hydrogen-bond basicity of imidazolium-based chloride ILs was mainly derived from chloride anion $\left(\mathrm{Cl}^{-}\right)$. Protic cosolvents, like $\mathrm{H}_{2} \mathrm{O}$ and $\mathrm{MeOH}$, bearing strong proton donating ability could interact with $\mathrm{Cl}^{-}$of $[\mathrm{Hmim}] \mathrm{Cl}$ through hydrogen-bond pattern. As a result, the $\beta$ of $\mathrm{Cl}^{-}$was crippled by the solvation of $\mathrm{Cl}^{-}$with protic cosolvents and the concentration of dissociated $\mathrm{Cl}^{-}$to interact with NA suffered a corresponding decrease, which together caused that the preferential solvation of NA by IL turned out to be unremarkable. Besides, due to the $\beta$ of $\mathrm{MeOH}$ was closer to that of pure IL than $\mathrm{H}_{2} \mathrm{O}, \beta$ tended to be linear against IL concentration in $[\mathrm{Hmim}] \mathrm{Cl}+\mathrm{MeOH}$ mixture while $[\mathrm{Hmim}] \mathrm{Cl}_{+} \mathrm{H}_{2} \mathrm{O}$ was featured by a relatively conspicuous nonlinearity. In contrast, ACN, DMSO and DMF belonged to typical dipolar aprotic solvents whose interactions with $\mathrm{Cl}^{-}$ might be greatly impaired, which could not only maintain the original hydrogen-bond basicity of $\mathrm{Cl}^{-}$but also in some degree produced more "free" $\mathrm{Cl}^{-}$to interact with NA compared with protic solvents. Even in slight addition of $\mathrm{IL}$ an equivalent strength of $\mathrm{Cl}^{-}$around NA in mixture to that of $\mathrm{Cl}^{-}$in pure IL was able to be achieved. Therefore, a favorable interaction between indicator and IL was uncovered particularly in IL dilute 
region, giving rise to a positive deviation from idea $\beta$. A careful look at DMF or $\mathrm{ACN}$ with $[\mathrm{Hmim}] \mathrm{Cl}$ would perceive, in specific composition range, $\beta$ became seemingly even higher than that of neat $[\mathrm{Hmim}] \mathrm{Cl}$ which might be ascribed to specific solvent complex formed in the mixture [34].

It should be pointed out that in mixtures of dipolar aprotic solvents, DMF, DMSO and ACN, a molar fraction of imidazolium-base chlorides ILs less than 0.1 was enough to alter $\beta$ to a high value, which would be of crucial significance in practical application. Especially in separation process that depended on hydrogen-bonding interaction as the main mechanism, like dissolution or extraction of acidic materials, good separation efficiency could be achieved as adding only small quantity of ILs into these aprotic cosolvents. An access of IL in mixture would not merely generate cost increasing and viscosity lifting but also result in lower separating performance instead. This deduction was verified by the research of extractive separation of tocopherol homologues by $[\mathrm{Bmim}] \mathrm{Cl}+\mathrm{ACN}$ binary mixture [32].

\subsection{Hydrogen-Bond Acidity ( $\alpha$ )}

Hydrogen-bond acidity reflected the ability of hydrogen-bond donator to accept electron pairs [15]. With reference to the 1,3-dialkyl substituted imidazolium ILs, hydrogen-bond acidity mainly stemmed from C2 hydrogen in imidazolium ring [35]. According to Kamlet-Taft solvatochromic method, $\alpha$ could be calculated from $E_{T}(30)$ and $\pi^{\star}$ through Eq. (4):

$\alpha=0.0649 E_{T}(30)-2.03-0.72 \pi$

Where $\pi^{*}$ was the dipolarity/polarizability obtained from DENA and $E_{T}(30)$ was the integrated "polarity" from 2,6-diphenyl-4-(2,4,6-triphenyl-N-pyridino) phenolate (Reichardt's dye), which could be acquired directly from electronic transition energy in Eq. (5):

$E_{T}(30)=h c v_{R d} N_{A}=2.8591 v_{R d}$

Where $h$ was the Planck constant, c was the velocity of light, $\mathrm{N}_{\mathrm{A}}$ was the Avogadro number and $v_{\mathrm{Rd}}$ was maximum absorption wave number of Reichardt's dye in solvent. Based on the molecular structure of Reichardt's dye, $E_{T}(30)$ manifested combined outcome of dipolarity/polarizability $\left(\pi^{\star}\right)$ and hydrogen-bond acidity ( $\alpha$ ), so $\alpha$ could be estimated via Eq. (4). Table 1 showed $\alpha$ values for series of imidazolium-based chloride ILs and cosolvents giving that $\mathrm{MeOH}$ owned a much higher value than ILs while $\alpha$ of the remaining cosolvents were less than ILs.

This part focused on two ILs, $[\mathrm{Bmim}] \mathrm{Cl}$ and $[\mathrm{Hmim}] \mathrm{Cl}$, with $\mathrm{MeOH}, \mathrm{DMF}, \mathrm{DMSO}$ and $\mathrm{ACN}\left(\mathrm{IL}+\mathrm{H}_{2} \mathrm{O}\right.$ mixture was not covered for reason that Reichardt's dye could hardly be dissolved in $\mathrm{H}_{2} \mathrm{O}$ ). The result of $\mathrm{IL}+$ cosolvent mixtures displayed in Figures $\mathbf{8}$ and $\mathbf{9}$ almost behaved in the same way, and we cited $[\mathrm{Hmim}] \mathrm{Cl}+\mathrm{cos} o l v e n t$ systems for discussion. As for the four cosolvents, there existed three variation tendencies of $\alpha$ depicted in Figure 8 . In $[\mathrm{Hmim}] \mathrm{Cl}+\mathrm{MeOH}$ mixture, $\alpha$ gradually went down by

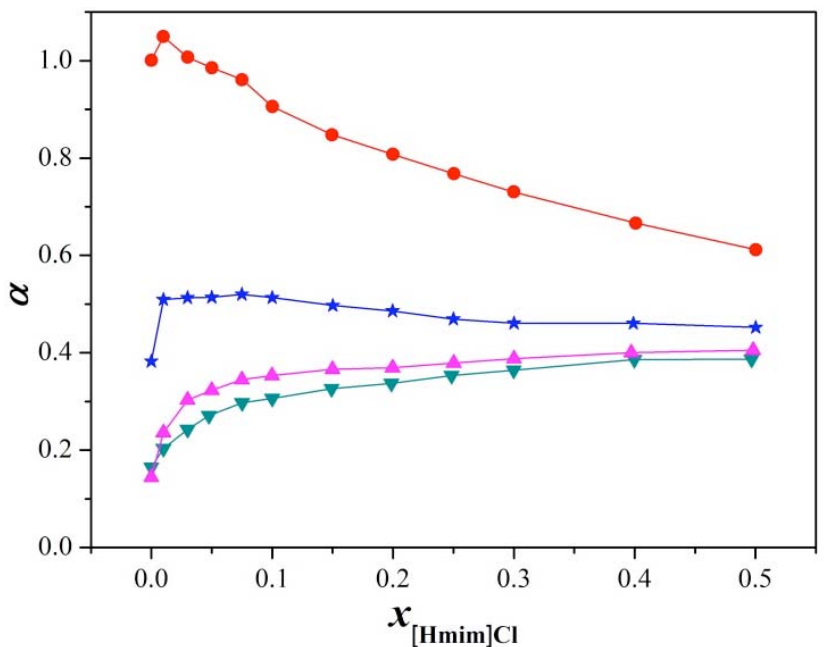

Figure 8: The performance of hydrogen-bond acidity $(\alpha)$ of $[\mathrm{Hmim}] \mathrm{Cl}+$ cosolvent mixtures over the molar fraction of $[\mathrm{Hmim}] \mathrm{Cl}\left(x_{[\mathrm{Hmim}] \mathrm{Cl}}\right)$ at $308 \mathrm{~K}$ : red line $(\mathrm{MeOH})$, blue line $(A C N)$, green line (DMSO) and rose line (DMF).

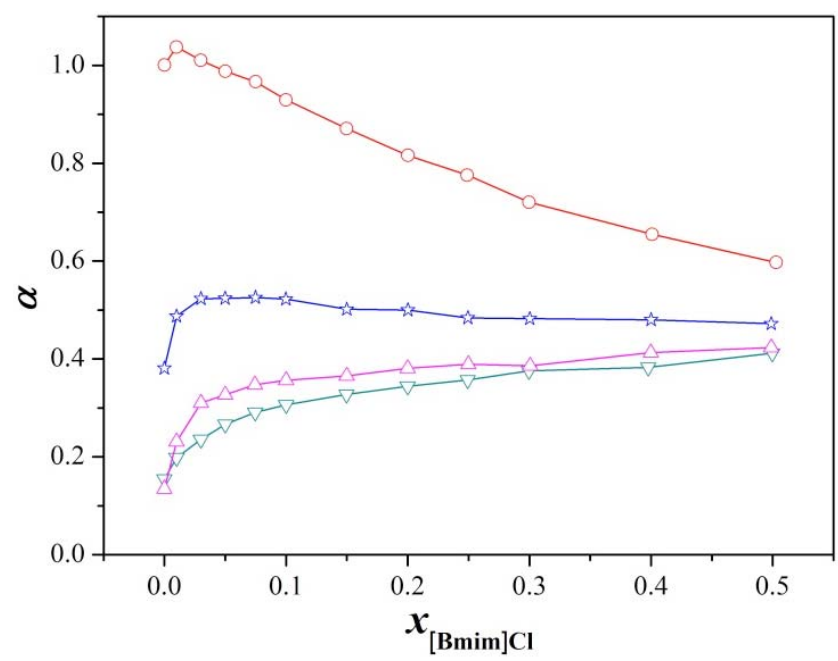

Figure 9: The performance of hydrogen-bond acidity $(\alpha)$ of $[\mathrm{Bmim}] \mathrm{Cl}+$ cosolvent mixtures over the molar fraction of $[\mathrm{Bmim}] \mathrm{Cl}\left(x_{[\mathrm{Bmim}] \mathrm{Cl}}\right)$ at $308 \mathrm{~K}$ : red line $(\mathrm{MeOH})$, blue line $(\mathrm{ACN})$, green line (DMSO) and rose line (DMF). 
augmenting $[\mathrm{Hmim}] \mathrm{Cl}$ concentration since the $\alpha$ of $[\mathrm{Hmim}] \mathrm{Cl}$ was weaker than $\mathrm{MeOH}$, and the downtrend gradually approached linearity. This behavior was likely to be caused by two factors. For one side, $\alpha$ of $\mathrm{MeOH}$ was apparently higher than that of $\mathrm{IL}$, hence, the solvation of hydrogen-bond basic probe molecule was apt to be dominated by $\mathrm{MeOH}$ molecule, which would generate a positive deviation of $\alpha$ from ideal behavior. On the other side, the hydrogen-bond interaction between $\mathrm{Cl}^{-}$of IL and hydroxyl of $\mathrm{MeOH}$ resulted in a weakened $\alpha$ value and less acting sites in mixture than pure $\mathrm{MeOH}$. The two factors exerted opposite impacts on $\alpha$ of $[\mathrm{Hmim}] \mathrm{Cl}+\mathrm{MeOH}$ mixture so that it approximated the ideal $\alpha$ and showed trend of linearity. Concerning $[\mathrm{Hmim}] \mathrm{Cl}+\mathrm{ACN}$ mixture, with the involvement of $[\mathrm{Hmim}] \mathrm{Cl} \alpha$ quickly reached a very high value in dilute region and then declined marginally later on. It was expected that the existence of peak $\alpha$ implied the formation of a more acidic complex of solvents in some composition range. Unlike the case in ACN, $\alpha$ kept a tendency of gradual rise in the whole composition range while the rising rate gradually slowed down in $[\mathrm{Hmim}] \mathrm{Cl}+\mathrm{DMF}$ and $[\mathrm{Hmim}] \mathrm{Cl}+\mathrm{DMSO}$ mixtures. We could see the performance of $\alpha$ was deviated from ideal condition in all aprotic cosolvents ACN, DMF and DMSO, which once again proved probe molecule was preferentially solvated by $[\mathrm{Hmim}] \mathrm{Cl}$. Based on the previous discuss of hydrogen-bond basicity $(\beta)$, the reason might also be ascribe to the weak interaction of $[\mathrm{Hmim}] \mathrm{Cl}$ and aprotic solvents to keep the hydrogen-bond acidity of $[\mathrm{Hmim}]^{+}$close to its pure-state value and also produce more "free" [Hmim $]^{+}$ to interact with probe molecule.

\section{CONCLUSION}

In summary, the performance of Kamlet-Taft solvatochromic parameters $\left(\pi^{*}, \beta, \alpha\right)$ in $\mathrm{IL}+$ cosolvent mixtures could be altered by IL structures and cosolvent types owing to solute-solvent and solventsolvent interactions. $\pi^{\star}$ of mixtures were mainly determined by the nature of pure ILs or cosolvents, and the variation of cation of ILs was effective at altering $\pi^{\star}$ of $\mathrm{IL}+\mathrm{H}_{2} \mathrm{O}$ mixtures mainly by changed hydrophobicity while made negligible effect on $\beta$ or $\alpha$. The manifestation that probe molecule was dominated by ILs could be obviously observed in $\beta$ or $\alpha$ of ILs with dipolar aprotic cosolvents while the hydrogen-bond interactions between ILs and dipolar protic cosolvents, like $\mathrm{H}_{2} \mathrm{O}$ and $\mathrm{MeOH}$, enabled preferential solvation to be alleviated. Besides, there is likely to be presence of solvent complex in specific composition where solvatochromic parameters were even higher than those of neat ILs and cosolvents. The above mentioned results are instructive for the understanding and design of IL+cosolvent mixtures for better performance of ILbased applications such as biomass dissolution and extraction, which provides opportunities of tuning the thermodynamic solvent-solute interactions by the polarity of solvent.

\section{ACKNOWLEDGEMENT}

The research was supported by the National Natural Science Foundation of China $(21222601,21436010$, U1162126), the Zhejiang Provincial Natural Science Foundation of China (LR13B060001) and Fundamental Research Funds for the Central Universities of China (2014XZZX003-17).

\section{REFERENCES}

[1] Brennecke JF, Maginn EJ. Ionic liquids: innovative fluids for chemical processing. AIChE J 2001; 47: 2384-9. http://dx.doi.org/10.1002/aic.690471102

[2] Pandey S. Analytical applications of room-temperature ionic liquids: a review of recent efforts. Anal Chim Acta 2006; 556: 38-45.

http://dx.doi.org/10.1016/j.aca.2005.06.038

[3] Plechkova NV, Seddon KR. Applications of ionic liquids in the chemical industry. Chem Soc Rev 2007; 37: 123. http://dx.doi.org/10.1039/b006677j

[4] Hallett JP, Welton T. Room-temperature ionic liquids: solvents for synthesis and catalysis. 2. Chem Rev 2011; 111: 3508-76.

http://dx.doi.org/10.1021/cr1003248

[5] Swatloski RP, Spear SK, Holbrey JD, Rogers RD. Dissolution of cellose with ionic liquids. J Am Chem Soc 2002; 124 : 4974-5.

http://dx.doi.org/10.1021/ja025790m

[6] Mäki-Arvela P, Anugwom I, Virtanen P, Sjöholm R, Mikkola JP. Dissolution of lignocellulosic materials and its constituents using ionic liquids-a review. Ind Crop Prod 2010; 32: 175-201.

http://dx.doi.org/10.1016/j.indcrop.2010.04.005

[7] Yang $Q$, Xing $H$, Cao $Y$, et al. Selective separation of tocopherol homologues by liquid-liquid extraction using ionic liquids. Ind Eng Chem Res 2009; 48: 6417-22. http://dx.doi.org/10.1021/ie801847e

[8] Pereiro AB, Araújo JMM, Esperança JMSS, Marrucho IM Rebelo LPN. Ionic liquids in separations of azeotropic systems-a review. J Chem Thermodyn 2012; 46: 2-28. http://dx.doi.org/10.1016/j.jct.2011.05.026

[9] Qin G, Song $Y$, Jin R, et al. Gas-liquid acetylene hydrochlorination under nonmercuric catalysis using ionic liquids as reaction media. Green Chem 2011; 13: 1495. http://dx.doi.org/10.1039/c1gc15041c

[10] Snelders DJM, Dyson PJ. Efficient synthesis of $\beta$ chlorovinylketones from acetylene in chloroaluminate ionic liquids. Org Lett 2011; 13: 4048-51. http://dx.doi.org/10.1021/ol201182t

[11] Comminges $C$, Barhdadi $R$, Laurent $M$, Troupel $M$. Determination of viscosity, ionic conductivity, and diffusion coefficients in some binary systems: ionic liquids + molecular solvents. Journal of Chemical \& Engineering Data 2006; 51: 680-5.

http://dx.doi.org/10.1021/je0504515 
[12] Chakrabarty D, Chakraborty A, Seth D, Sarkar N. Effect of Water, Methanol, and acetonitrile on solvent relaxation and rotational relaxation of Coumarin 153 in neat 1-hexyl-3methylimidazolium hexafluorophosphate. J Phys Chem A 2005; 109: 1764-9. http://dx.doi.org/10.1021/jp0460339

[13] Yang QW, Yu K, Xing HB, et al. The effect of molecular solvents on the viscosity, conductivity and ionicity of mixtures containing chloride anion-based ionic liquid. J Ind Eng Chem 2013; 19: 1708-14. http://dx.doi.org/10.1016/j.jiec.2013.02.010

[14] Ab Rani MA, Brant A, Crowhurst L, et al. Understanding the polarity of ionic liquids. Phys Chem Chem Phys 2011; 13: 16831-40. http://dx.doi.org/10.1039/c1cp21262a

[15] Taft RW, Kamlet MJ. The solvatochromic comparison method. 2. The $\alpha$-scale of solvent hydrogen-bond donor (HBD) acidities. J Am Chem Soc 1976; 98: 2886-94. http://dx.doi.org/10.1021/ja00426a036

[16] Kamlet MJ, Taft RW. The solvatochromic comparison method. I. The $\beta$-scale of solvent hydrogen-bond acceptor (HBA) basicities. J Am Chem Soc 1976; 98: 377-83. http://dx.doi.org/10.1021/ja00418a009

[17] Kamlet MJ, Abboud JL, Taft RW. The solvatochromic comparison method. 6 . The $\pi^{*}$ scale of solvent polarities. J Am Chem Soc 1977; 99: 6027-38. http://dx.doi.org/10.1021/ja00460a031

[18] Crowhurst L, Mawdsley PR, Perez-Arlandis JM, Salter PA, Welton T. Solvent-solute interactions in ionic liquids. Phys Chem Chem Phys 2003; 5: 2790. http://dx.doi.org/10.1039/b303095d

[19] Jessop PG, Jessop DA, Fu D, Phan L. Solvatochromic parameters for solvents of interest in green chemistry. Green Chem 2012; 14: 1245. http://dx.doi.org/10.1039/c2gc16670d

[20] Jelič ić A, García N, Lö hmannsrö ben H, Beuermann S. Prediction of the ionic liquid influence on propagation rate coefficients in methyl methacrylate radical polymerizations based on Kamlet-Taft solvatochromic parameters. Macromolecules 2009; 42: 8801-8. http://dx.doi.org/10.1021/ma9017907

[21] Wu Y, Sasaki T, Kazushi K, Seo T, Sakurai K. Interactions between spiropyrans and room-temperature ionic liquids: photochromism and solvatochromism. J Phys Chem B 2008; 112: 7530-6.

http://dx.doi.org/10.1021/jp800957c

[22] Task specific ionic liquids for cellulose technology.

[23] Chiappe C, Pomelli CS, Rajamani S. Influence of structural variations in cationic and anionic moieties on the polarity of ionic liquids. J Phys Chem B 2011; 115: 9653-61. http://dx.doi.org/10.1021/jp2045788

[24] Khupse ND, Kumar A. Delineating solute-solvent interactions in binary mixtures of ionic liquids in molecular solvents and preferential solvation approach. J Phys Chem B 2011; 115: 711-8.

http://dx.doi.org/10.1021/jp110040a
[25] Salari H, Khodadadi-Moghaddam M, Harifi-Mood AR, Gholami MR. Preferential solvation and behavior of solvatochromic indicators in mixtures of an ionic liquid with some molecular solvents. J Phys Chem B 2010; 114: 958693.

http://dx.doi.org/10.1021/jp103476a

[26] Mellein BR, Aki SNVK, Ladewski RL, Brennecke JF. Solvatochromic studies of ionic liquid/organic mixtures. J Phys Chem B 2007; 111: 131-8.

http://dx.doi.org/10.1021/jp0653353

[27] Sarkar A, Pandey S. Solvatochromic absorbance probe behavior and preferential solvation in aqueous 1-butyl-3methylimidazolium tetrafluoroborate. Journal of Chemical \& Engineering Data 2006; 51: 2051-5. http://dx.doi.org/10.1021/je0601560

[28] Ali A, Ali M, Malik NA, Uzair S, Khan AB. Solvatochromic absorbance probe behavior within mixtures of the ionic liquid 1-butyl-3-methylimidazolium bis(trifluoromethylsulfonyl)imide + molecular organic solvents. Journal of Chemical \& Engineering Data 2014; 59: 1755-65.

http://dx.doi.org/10.1021/je400908z

[29] Harifi-Mood AR, Habibi-Yangjeh A, Gholami MR. Solvatochromic parameters for binary mixtures of 1-(1-butyl)3-methylimidazolium tetrafluoroborate with some protic molecular solvents. J Phys Chem B 2006; 110: 7073-8. http://dx.doi.org/10.1021/jp0602373

[30] Yang QW, Xing HB, Cao YF, et al. Selective separation of tocopherol homologues by liquid-liquid extraction using ionic liquids. Ind Eng Chem Res 2009; 48: 6417-22. http://dx.doi.org/10.1021/ie801847e

[31] Hubbard CD, Illner P, van Eldik R. Understanding chemical reaction mechanisms in ionic liquids: successes and challenges. Chem Soc Rev 2011; 40: 272-90. http://dx.doi.org/10.1039/c0cs00043d

[32] Yang $Q$, Xing $H$, Su B, et al. Improved separation efficiency using ionic liquid-cosolvent mixtures as the extractant in liquid-liquid extraction: a multiple adjustment and synergistic effect. Chem Eng J 2012; 181-182: 334-42. http://dx.doi.org/10.1016/j.cej.2011.11.089

[33] Fukaya $Y$, Sugimoto A, Ohno $H$. Superior solubility of polysaccharides in low viscosity, polar, and halogen-free 1,3dialkylimidazolium formates. Biomacromolecules 2006; 7: 3295-7.

http://dx.doi.org/10.1021/bm060327d

[34] Marcus Y. Use of chemical probes for the characterization of solvent mixtures. 1. Completely nonaqueous mixtures. J Chem Soc Perkin Trans 2 1994: 1015-21. http://dx.doi.org/10.1039/p29940001015

[35] Muldoon MJ, Gordon CM, Dunkin IR. Investigations of solvent-solute interactions in room temperature ionic liquids using solvatochromic dyes. J Chem Soc Perkin Trans 2 2001: 433-5.

http://dx.doi.org/10.1039/b101449h

\section{DOI: http://dx.doi.org/10.6000/1929-5030.2014.03.04.4}

(C) 2014 Hu et al.; Licensee Lifescience Global.

This is an open access article licensed under the terms of the Creative Commons Attribution Non-Commercial License (http://creativecommons.org/licenses/by-nc/3.0/) which permits unrestricted, non-commercial use, distribution and reproduction in any medium, provided the work is properly cited. 